\title{
Importância da calagem, adubações tradicionais e alternativas na produção de plantas forrageiras: Revisão
}

\author{
Marcos Paulo dos Santos ${ }^{1 *}$, Yuri de Oliveira Castro ${ }^{1}$, Renata de Castro Marques ${ }^{1}$, \\ Débora Regina Marques Pereira ${ }^{1}$, Marcelo Marcondes de Godoy ${ }^{2}$ e Nívea Patrícia \\ Ribeiro Reges ${ }^{3}$
}

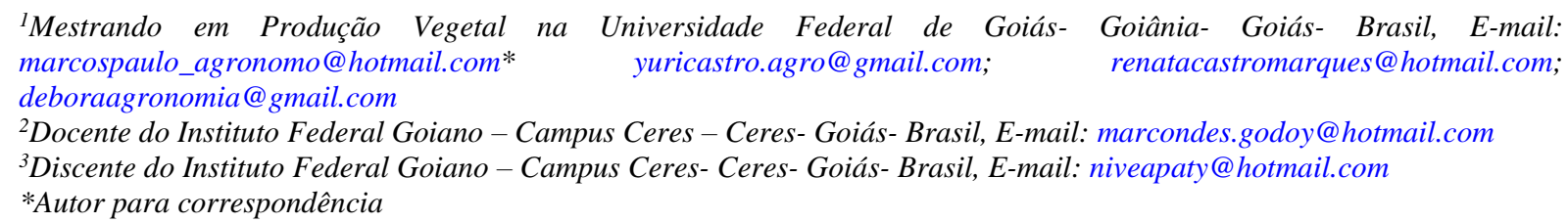

RESUMO. As áreas de pastagens são responsáveis pelo alojamento de aproximadamente 2/3 do rebanho nacional, a busca pela otimização do uso dessas áreas se faz necessária devido à limitação da abertura de novas áreas para exploração agrícola e pecuária no território nacional. A manutenção e/ou melhoria das características físico-químicas do solo, e também da atividade microbiológica tem sido estudada e aprimorada visando maximizar os desempenhos de forrageiras propícias ao consumo animal. Inovações quanto aos métodos de aplicação de fertilizantes, estratégias de cultivo e aproveitamento de resíduos de outras atividades tem sido enfoque de várias pesquisas no país. Esta revisão aborda as principais estratégias de adubação que vem sendo incorporadas aos sistemas de produção animal utilizadas atualmente na pecuária brasileira.

Palavras chaves: consórcio, fósforo, gramíneas, leguminosas, nitrogênio, potássio.

\section{Importance of limestone and fertilization in traditional and alternative production of forage plants}

\begin{abstract}
The pasture areas are responsible for approximately $2 / 3$ of the national herd accommodation; the search for the optimal use of these areas is required due to limited opening of new areas for farming and ranching in the country. The maintenance and / or improvement of the physico-chemical characteristics of the soil, and also the microbial activity has been studied and enhanced to maximize the performances of favorable forage for animal consumption. Innovations for methods of fertilizer application, cropping strategies and use of waste other activities have been focused by many researchers in the country. This review addresses the main strategies of fertilizer that has been incorporated into animal production systems, emphasizing the need to disseminate these strategies for the Brazilian cattle livestock becomes more competitive.
\end{abstract}

Keywords: consortium, phosphorus, grasses, legumes, nitrogen, potassium

\section{Introdução}

A pecuária, em particular a criação de bovinos de corte a pasto, tem sido a atividade historicamente empregada na ocupação de áreas de fronteira agrícola por ser a forma menos onerosa e mais eficiente para ocupar e assegurar a posse de grandes extensões de terra (DiasFilho, 2014). No Brasil estima-se que 95\% do rebanho bovino seja criado a pasto (Ferraz \& Felício, 2010), no ano de 2012 a área de pastagens (natural e cultivada) era da ordem 220 milhões de hectares, o que representava $25 \%$ dos 851 milhões de hectares do território nacional, a taxa de lotação média do país era de apenas um animal por hectare, característica da pecuária essencialmente extensiva (Guina et al., 2012), evidenciando assim a importância de se 
estabelecer estratégias de manejo para intensificação da pecuária nacional. A adubação de pastagens é uma prática agrícola utilizada pelos pecuaristas de todo mundo há muitos anos, visando potencializar o desenvolvimento $\mathrm{e}$ aumentar a produtividade das forrageiras destinadas ao consumo animal, através da aplicação de nutrientes no solo para recuperação ou conservação de sua fertilidade.

Tradicionalmente a adubação de pastagens tem sido feita com o intuito de intensificar a produção animal, reduzir a sazonalidade de produção, evitar a degradação e/ou recuperar áreas de pastagens degradadas, no entanto objetivos inovadores como o aumento da flexibilidade de manejo, aproveitamento de resíduos agroindustriais, aumento da fixação de carbono e a preservação dos recursos naturais estão ganhando enfoque no que se diz respeito à produção forrageira (Fonseca et al., 2011).

Inovações tecnológicas como a fertiirrigação, pastejo rotacionado, adubações alternativas (esterco bovino, cama de frango, vinhaça) têm contribuído para a intensificação dos sistemas produtivos, permitindo aumentar a produção de forragem por unidade de área. A adubação nitrogenada, potássica e fosfatada comumente utilizadas nos sistemas intensivos de produção para promover maior acúmulo de massa verde/ha, visa à reposição ao solo dos nutrientes que as plantas absorvem e são exportados pelos animais, além daqueles que foram lixiviados ou perdidos através de outros meios como a volatilização, desnitrificação e/ou imobilização (Herling \& Luz, 2001), visa também à elevação, em determinados solos, dos teores de nutrientes que estão, originalmente ou por intervenção humana, em níveis muito baixos dos que são exigidos para o cultivo da cultura que se desejar estabelecer.

No entanto essa devolução de nutrientes ao solo através da adubação, quando realizada de forma errônea, ou seja, sem orientação técnica, além de inviabilizar o sistema produtivo devido ao seu alto custo, acarreta inúmeros malefícios ao meio ambiente como eutrofização de cursos d'água e salinização do solo, que consequentemente resultarão em sistemas menos produtivos e degradados.

Segundo Santos et al. (2009) a prática de reposição de nutrientes através da adubação é fundamental para elevação e manutenção da quantidade e qualidade da forragem a pasto. É evidente que o solo é o principal componente fornecedor de elementos químicos para as plantas, não apenas os considerados essenciais como também aqueles classificados como benéficos, como o sódio, silício, selênio, cobalto, e os elementos tóxicos como o alumínio, mercúrio, cromo, chumbo etc. Há evidências nas pastagens brasileiras, de sucessos da utilização planejada de adubos como ureia, super fosfato simples e cloreto de potássio como fonte de nitrogênio $(\mathrm{N})$, fósforo $(\mathrm{P})$ e potássio $(\mathrm{K})$, respectivamente, assim como de pastagens consorciadas com leguminosas, dentre elas o calopogônio, crotalária juncea, crotalária vistosa, estilosantes, mucuna, feijão de porco etc, e cultivos isolados dessas culturas servindo de bancos de proteínas para os animais.

O aproveitamento de resíduos agrícolas e industriais como fertilizantes constitui uma estratégia importante na adubação de pastagens. Normalmente, esses resíduos, quando produzidos em grande quantidade, podem gerar problemas ambientais. Contudo, seu uso racional em pastagens pode ser adequado e benéfico ao sistema de produção. Os dejetos de bovinos e suínos, escória de siderurgia, vinhaça (fonte de potássio) são exemplos de resíduos que podem ser usados na adubação corretiva e de formação das pastagens (Fonseca et al., 2011).

Outro fator limitante para o desenvolvimento das forrageiras, principalmente nas regiões de cerrado, é a acidez do solo, que reduz o crescimento radicular das forrageiras (gramíneas e leguminosas) através da intoxicação das raízes por $\mathrm{Al}^{+3}$, e ainda diminui a atividade das bactérias fixadoras de nitrogênio nestas últimas (Sousa et al., 2001). A calagem e a gessagem são estratégias que possibilitam as plantas forrageiras um melhor desenvolvimento nessas regiões, pois reduzem a acidez do solo permitindo uma maior disponibilidade de nutrientes favorecendo $o$ crescimento do sistema radicular das mesmas (Santos et al., 2009). Estudos de Prado \& Fernandes (2000) e Prado et al. (2003) aplicando escórias de siderúrgicas ao solo demonstraram aumento de $\mathrm{pH}$ e redução do $\mathrm{H}+\mathrm{Al}$, podendo vir a ser uma alternativa promissora para corrigir a acidez do solo em áreas de pastagens.

Esta revisão tem como objetivo, abordar as estratégias de manejo das adubações tradicionais e alternativas utilizadas atualmente, evidenciando os benefícios das inovações tecnológicas empregadas nas áreas pastoris em sistemas intensivos de produção a pasto. 


\section{Revisão de literatura}

\section{Calagem e gessagem}

Ao longo de muitos anos a pecuária esteve baseada principalmente na exploração de pastagens nativas, mas no decorrer das três últimas décadas, o crescimento acentuado do rebanho bovino e o elevado aumento na capacidade de suporte das pastagens foram provenientes da exploração de novas áreas e do maior uso de forrageiras de outros continentes, como as dos gêneros Urochloa e Andropogon (Sousa et al., 2001).

$\mathrm{O}$ cerrado foi a principal área abrangida pelo aumento das fronteiras agrícolas, apesar de apresentar características químicas do solo desfavoráveis ao crescimento e desenvolvimento forrageiro, como elevada acidez e baixa capacidade de troca catiônica (CTC), este bioma têm sido explorado fortemente pelos pecuaristas, graças ao uso da calagem que corrige a deficiência de cálcio e magnésio, elevando assim o pH do solo e diminuindo a toxidez de alumínio ao sistema radicular, aliada à implantação de forrageiras tropicais resistentes a acidez do solo (Sousa et al., 2001).

No entanto a calagem corrige apenas a sub superfície do solo, isto é, a camada abaixo da qual se incorporou o calcário, mantendo o subsolo praticamente inalterado quanto à toxidez de alumínio. Assim, o crescimento do sistema radicular das plantas forrageiras fica limitado apenas à camada subsuperficial, podendo esta situação ser agravada em épocas de veranico, quando há interrupção da precipitação reduzindo a umidade do solo na camada superficial (zona de maior crescimento radicular) e por conseqüência da toxidez não corrigida no subsolo as raízes não conseguem penetrar nas camadas mais profundas do solo para absorver água, ficando o agricultor sujeito a perdas de produtividade. Neste sentido a utilização do gesso agrícola surge como opção para potencializar o efeito da calagem e aumentar o desenvolvimento do sistema radicular (Vilela, 2009).

O gesso é um subproduto da indústria de fertilizantes fosfatados, contém em média cerca de $15 \%$ de enxofre e $19 \%$ de cálcio. Ao se aplicar o gesso, o sulfato se movimenta para o subsolo acompanho por cátions, especialmente o cálcio, corrigindo a acidez do solo em camadas mais profundas e diminuindo os teores de alumínio. De acordo com Sousa et al. (2001) a aplicação do gesso, no solo úmido, favorece a penetração do cálcio. Dessa forma, ele favorece $o$ aprofundamento das raízes e permite maior resistência das plantas a escassez de água em períodos de veranico. Além da água, os nutrientes podem ser absorvidos com maior eficiência em camadas mais profundas do solo.

\section{Respostas de forrageiras à utilização de gesso e calcário}

Mesquita et al. (2002) verificaram que com o aumento da proporção gesso/calcário houve melhoria da qualidade da forragem, elevando os teores de S, Ca e proteína bruta na matéria seca (MS) de braquiária e estilosantes, e reduzindo os teores de fibra em detergente neutro da braquiária.

Em estudo realizado por Oliveira et al. (2009) foi verificado que a aplicação de cálcio na fonte de gesso resultou em maior produção de massa seca de Urochloa brizantha cv. Marandu, solteira e consorciada. A calagem promoveu maiores concentrações de cálcio e a gessagem maiores concentrações de enxofre no tecido foliar em todos os sistemas, sendo maiores nos consorciados. Segundo os autores maior ênfase deve ser dada a aplicação do gesso agrícola por aumentar os níveis de enxofre que é importante para maximizar a resposta da forrageira, principalmente em áreas degradadas, com baixos teores de matéria orgânica, onde, normalmente, os teores de enxofre-sulfato se encontram com baixa disponibilidade no solo.

A calagem, tanto na ausência quanto na presença de gesso, aumentou os teores de $\mathrm{N}$ nas folhas de sorgo, em consequência da elevação do $\mathrm{pH}$ na camada superficial, que proporcionou maior mineralização de $\mathrm{N}$ orgânico do solo, e promoveu efeito quadrático na produção de matéria seca do sorgo pela diminuição do alumínio $\left(\mathrm{Al}^{3+}\right)$ em função da calagem. O número de grãos por panícula assim como o número de panículas por $\mathrm{m}^{2}$ aumentou em função do aumento das doses de calagem preconizadas (Costa, 2011).

Em estudo realizado por Fruchi et al. (2007) a aplicação de gesso agrícola em soqueira de quarto corte de cana, proporcionou tendência de aumento do número de colmos nas fases iniciais, assim como na produtividade de colmos por hectare. A aplicação de escórias de siderurgia no solo têm demonstrado aumento de $\mathrm{pH}$ e redução do $\mathrm{H}+\mathrm{Al}$ (Prado \& Fernandes, 2000, Prado et al., 
2003) em razão da presença de agentes neutralizantes da acidez como o $\mathrm{SiO}_{3}{ }^{-2}$. Felipe (2012) verificou que a aplicação superficial de doses crescentes de agrosilício ${ }^{\circledR}$ (subproduto do beneficiamento de escórias de siderurgia) promoveu melhoria nos atributos químicos de um solo sob consórcio milho e braquiária. Houve aumento linear nos valores de $\mathrm{pH}, \mathrm{V} \%$, nos teores de bases ( $\mathrm{Ca}$ e $\mathrm{Mg}$ ), além da redução nos teores de $\mathrm{Al}^{3+}$ e consequentemente da saturação de alumínio (m\%) nas camadas de 0-5, 5-10 e 10$20 \mathrm{~cm}$.

Stocco et al. (2010) verificaram influência das doses de silicato aplicadas, na forma de escórias, sobre o desenvolvimento das gramíneas $U$. brizantha e $U$. decumbens. Os autores utilizaram duas fontes de escórias, sendo elas, escória A (7,23\% de $\mathrm{SiO}_{2}, 45,1 \%$ de $\mathrm{CaO}$ e $9,9 \%$ de $\left.\mathrm{MgO}\right)$ e escória $\mathrm{B}\left(21,30 \%\right.$ de $\mathrm{SiO}_{2}, 37,0 \%$ de $\mathrm{CaO}$ e $12,6 \%$ de $\mathrm{MgO}$ ), e verificaram que a escória do tipo $\mathrm{B}$ foi superior à escória $\mathrm{A}$, no primeiro corte e na somatória dos cortes, quanto à produção de matéria seca e perfilhamento das gramíneas. A $U$. brizantha, associada à escória $\mathrm{B}$, apresentou maior produção de matéria seca da parte aérea em relação à $U$. decumbens, evidenciando assim que o desempenho da espécie forrageira está fortemente associado com a introdução de agentes neutralizantes da acidez ativa do solo, podendo ser favorecido pela utilização de resíduos industriais como demonstrado neste estudo.

A produtividade de forrageiras em resposta a melhoria das condições químicas do solo, tem sido estudada em diferentes regiões do Brasil, e embora as técnicas de calagem, gessagem, bem como a utilização de resíduos industriais estejam se mostrando eficientes ferramentas para incremento da produtividade e qualidade das forrageiras cultivadas, os dados disponíveis não permitem indicar uma estratégia de manejo específica para cada região em função das diferentes formas com que as forrageiras são manejadas nos sistemas pastoris. Desta maneira estudos mais detalhados, como o comportamento de cultivares de forrageiras em função das mesmas dosagens, fontes, épocas, formas, e profundidade de aplicação destes corretivos necessitam serem feitos em diferentes localidades do país, com o intuito de encontrar uma metodologia específica que possa ser indicada para o maior número de produtores possível.

\section{Adubação nitrogenada}

O nitrogênio é o principal nutriente das gramíneas, faz parte das moléculas primárias das proteínas e proporciona aumento imediato da produção de forragem. Solos deficientes em nitrogênio promovem crescimento lento, plantas de porte pequeno, com poucos perfilhos, e insuficiente teor de proteína bruta para a alimentação animal (Herling \& Luz, 2001). De acordo com Fonseca et al. (2011) a fonte de nitrogênio no solo é a matéria orgânica, porém não diretamente absorvida pelas plantas, sendo necessária sua decomposição pela ação de microrganismos, de forma a liberar $\mathrm{N}$ prontamente assimilável.

A adubação nitrogenada acelera o crescimento vegetal, gera um maior acúmulo de biomassa por unidade de área, e consequentemente aumenta a produção animal. Moreira (2000) avaliando a produção primária (primeira produção após formação do pasto) e secundária (rebrota após primeiro pastejo) da pastagem de $U$. decumbens cv. Basilisk (capim-braquiária) adubada com quatro doses de nitrogênio $(75,150,225$ e 300 $\mathrm{kg} / \mathrm{ha}$ de N) e manejada sob lotação variável a fim de manter a altura média do pasto em aproximadamente $20 \mathrm{~cm}$, verificou que, os pastos adubados com maiores doses de $\mathrm{N}$ expressaram maior taxa de crescimento e, consequentemente, superior acúmulo de forragem, o que tornou possível o aumento da taxa de lotação da pastagem para manter a altura média do pasto dentro da meta almejada, acarretando superior produção animal por unidade de área.

Na maioria dos casos a aplicação de $\mathrm{N}$ ocorre pela utilização de fertilizantes nitrogenados sintéticos que apresentam características de alta solubilidade facilitando assim a assimilação dos mesmos pelas forrageiras, diferentemente do que acontece com $\mathrm{N}$ orgânico. Entretanto a alta solubilidade dos fertilizantes sintéticos ocasiona altas perdas de $\mathrm{N}$ dentro do sistema em função da maior lixiviação deste elemento no solo, que de certa forma são indesejáveis e devem ser evitadas em sistemas intensivos de produção para minimizar os custos.

Atualmente a adubação nitrogenada tem sido empregada para facilitar a integração das ações de manejo nos sistemas produtivos, tornando-os mais flexíveis operacionalmente quanto à duração do período de diferimento e uso do pasto (Santos, 2010). 
$\mathrm{O}$ uso de fontes nitrogenadas menos solúveis, como a ureia protegida (mistura da ureia propriamente dita a um produtor comercial denominado de inibidor da urease, como é o caso do NBPT (N-(n-butil) tiofosfórico-triamida, visando à inibição da enzima urease pelo produto, que ocupa o local de atuação da urease e inativa a enzima retardando a perda de $\mathrm{N}$ amoniacal $\left(\mathrm{N}-\mathrm{NH}_{3}\right)$ para o ambiente por volatilização e permite o deslocamento da ureia para horizontes mais profundos do solo favorecendo assim o uso do $\mathrm{N}-\mathrm{NH}_{3}$ pela planta (Contin, 2007)), pode reduzir as perdas ocasionada pela alta solubilidade dos fertilizantes sintéticos tradicionais. Contin (2007) estudando o comportamento da cana de açúcar submetida à adubação nitrogenada, verificou incremento na produção de 7 a 16 t/ha nas áreas recebendo doses entre 50 e $150 \mathrm{~kg}$ de $\mathrm{N}^{-1}$ aplicados na forma protegida.

Sichocki et al. (2010) avaliando duas fontes de $\mathrm{N}$ (ureia convencional e protegida $\left(\right.$ Kincoat $^{\circledR}$ ) aplicadas nas dosagens de $(0,50,100,150,200 \mathrm{e}$ $400 \mathrm{~kg} \mathrm{ha}^{-1}$ ) na adubação de milho, verificaram diferença significativa para as fontes e doses utilizadas. A produtividade do milho foi superior quando se utilizou ureia protegida como fonte de $\mathrm{N}$ na dosagem de $200 \mathrm{~kg} \mathrm{ha}^{-1}$. Nas demais dosagens as fontes não diferiram estatisticamente entre si para a variável produtividade.

Outra forma de reduzir as perdas de $\mathrm{N}$ é a adoção de adubações estratégicas visando minimizar a estacionalidade de produção de forragem em pastagens. Costa et al. (2001) avaliaram o capim $U$. humidicola no estado de São Paulo, sob três épocas de aplicação do adubo nitrogenado (até $150 \mathrm{~kg} / \mathrm{ha} / \mathrm{ano}$ de $\mathrm{N}$ ), sendo: aplicação total em novembro; aplicação de 1/2 em novembro e 1/2 em março; aplicação de 1/3 em novembro e 2/3 em março. Quando a quantidade de $\mathrm{N}$ preconizada foi aplicada de uma só vez, a porcentagem da produção de forragem durante o "período de seca" foi de apenas $(8 \%)$ em relação à produção anual. Já quando $2 / 3$ do adubo nitrogenado foi aplicado em março, os autores verificaram maior participação do "período de seca" (22\%) na produção total anual da forrageira. Isso demonstra que o parcelamento da adubação nitrogenada é favorável e surte efeito na produção de biomassa por área ao longo do ano, fazendo com que esta estratégia seja indicada para estudos em outros materiais forrageiros utilizados atualmente na pecuária nacional para que os seus efeitos benéficos se tornem mais concisos.

Teixeira et al. (2011) testando quatro estratégias de adubação nitrogenada à base de ureia aplicadas no início e/ou fim do verão $(0-0$, 100-0, 50-50, 0-100 kg ha de $\mathrm{N}$ ), respectivamente, em dois períodos de diferimento (95 e 140 dias), verificaram que quando a aplicação foi feita no início do verão a maior produção de forragem se deu para o período de 95 dias de diferimento, enquanto a aplicação de $\mathrm{N}$ no final do verão não proporcionou diferença significativa no acúmulo de forragem entre os períodos de diferimento, e que quando a aplicação foi feita no final do verão ou de forma parcelada (50-50) no início e no final do verão, houve incremento na produção e no teor de proteína bruta, e redução do teor de FDN não diferindo entre os períodos analisados. Observaram-se neste trabalho incrementos na faixa de 31 e $25 \%$ na produção anual total de matéria seca em pastagens adubadas com $100 \mathrm{~kg}$ $\mathrm{ha}^{-1}$ de $\mathrm{N}$ no início do verão e diferidas por períodos de (95 e 140 dias) respectivamente, em comparação ao controle, caracterizando a interação entre doses de adubo e manejo do pasto.

A aplicação de nitrogênio com fontes com alta solubilidade e de liberação rápida como a ureia e/ou formulados comercias em épocas estratégicas, o uso de adubos nitrogenados menos solúveis e de liberação gradativa, e o manejo da aplicação de $\mathrm{N}$ em pastagens destinadas ao diferimento para acúmulo de forragem para ser utilizada no período seco, que na prática contribui para a redução da curva de sazonalidade da produção de forragem durante o ano, têm se mostrado ferramentas eficientes para redução das perdas de nitrogênio no sistema solo $\mathrm{x}$ planta $\mathrm{x}$ atmosfera, podendo servir como ponto de partida para novas possibilidades de estudos que otimizem a utilização do $\mathrm{N}$, aumentando a produtividade e reduzindo os custos decorrentes de sua aplicação.

\section{Adubação fosfatada}

O fósforo é exigido em menor quantidade pelas plantas quando comparado ao nitrogênio e ao potássio, sendo o mais demandado em adubação no Brasil. Isso ocorre devido sua baixa disponibilidade no solo aliada à forte interação com a argila, o que reduz sua absorção pelas plantas. O fósforo é encontrado na solução do 
solo como íon ortofosfato $\left(\mathrm{H}_{2} \mathrm{PO}_{4}{ }^{-}\right)$, sendo que a predominância desta forma é dependente do $\mathrm{pH}$ do solo (Fageria et al., 2004).

$\mathrm{O}$ fósforo $(\mathrm{P})$ é elemento essencial ao crescimento, desenvolvimento e reprodução das plantas com importante papel no processo de formação de sementes. É um elemento pouco móvel no solo e seu suprimento para as raízes é efetuado principalmente pelo processo de difusão, o qual depende da umidade do solo e da superfície radicular (Leão, 2006). A deficiência de fósforo pode alterar o desenvolvimento da planta de duas maneiras, atuando como nutriente que estimula a produção de fitomassa radicular, ou regulando mudanças na arquitetura radicular. A taxa de crescimento das plantas é reduzida desde os primeiros estádios de desenvolvimento, além disso, a deficiência de $\mathrm{P}$ é uma grande limitação para a fotossíntese e a sua baixa disponibilidade afeta a produção das culturas em 96\% dos solos ácidos e pouco férteis na América tropical (Fageria et al., 2004).

A eficiência da utilização de fósforo é evidente em todos os cultivos agrícolas. Gatiboni et al. (2013), variando fontes de fósforo, associadas ou não a calagem e à introdução de espécies forrageiras de inverno em pastagens naturais, verificaram maior produtividade de matéria seca, com a adição de fosfatos solúveis (superfosfato simples) e calagem, evidenciando ainda maior participação das espécies introduzidas na produção total de MS da parte aérea, fortalecendo assim a necessidade de correção das áreas pastoris. A baixa disponibilidade de fósforo nas regiões do cerrado no Brasil, em virtude de características físicas e químicas dos solos, tem sido preocupação para muitos produtores de grãos e pecuaristas. Uma alternativa que vem sendo estudada e aprimorada ao longo dos últimos anos quanto à utilização do fósforo tem sido a aplicação do mesmo via fosfato de rocha natural, a qual diminui as perdas por adsorção do elemento as partículas de argila, devido à menor solubilidade e tempo de reação no solo.

Guedes et al. (2009) comparando fontes de fósforo (solúvel e natural) sobre o crescimento de $U$. brizantha, concluíram que o fosfato natural de Arad foi mais eficiente para produção de massa seca do que super fosfato triplo a partir do segundo corte da forrageira com ou sem a correção do solo, uma vez que aumentou a produção de massa seca da parte aérea, de raízes e perfilhamento do braquiarão. Quanto a qualidade das forragens adubadas com fósforo podemos citar o trabalho de Sousa et al. (2010) onde a adubação fosfatada juntamente com a adubação nitrogenada proporcionou efeito quadrático nos teores de proteína bruta, fibra em detergente neutro e nutrientes digestíveis totais do capim Tanzânia cortado a cada 28 dias de crescimento, melhorando o valor nutritivo da forragem.

Outros trabalhos como os de Lima et al. (2007), Politi \& Prado (2009) e Santos et al. (2012) demonstraram que o uso da adubação fosfatada contribuiu significativamente para aumento da produção de MS de forragem por unidade de área, aumento da capacidade de rebrote assim como do perfilhamento das pastagens (Patês et al., 2007, Benício et al., 2011) e melhoria na qualidade nutricional da forrageira a ser ofertada aos animais (Krolow et al., 2004) tornando o seu uso essencial para aumento da eficiência produtiva do rebanho que, consequentemente, acarretará maior rentabilidade para a atividade pecuária. Diante desse cenário e tendo em vistas as condições limitantes no que diz respeito à fertilidade dos solos brasileiros, principalmente no bioma cerrado, justifica-se a adoção desta prática de adubação fosfatada associada com outras adubações, ou até mesmo de forma isolada antes do estabelecimento da pastagem, visando aumentar a capacidade de exploração das áreas pastoris nos sistemas de produção intensiva.

\section{Adubação potássica}

$\mathrm{O}$ potássio deve ser fornecido à planta em função da análise de solo, devido sua forte influência na produção de MS, principalmente em sistemas intensivos, onde do total extraído mediante pastejo, $99 \%$ é devolvido ao solo (Vilela, 2009).

$\mathrm{O} \mathrm{K}$ é o cátion mais abundante nos tecidos vegetais, sendo absorvido da solução do solo em grandes quantidades pelas raízes na forma do íon $\mathrm{K}^{+}$. Nos tecidos vegetais o $\mathrm{K}$ é encontrado livre ou adsorvido, o que o torna facilmente trocável das células ou dos tecidos, com alta mobilidade intracelular. As necessidades de $\mathrm{K}$ para o ótimo crescimento das plantas situam-se na faixa de 20$50 \mathrm{~g} \mathrm{~kg}^{-1}$ da massa seca das partes vegetativas das plantas, das frutas e dos tubérculos (Torres \& Pereira, 2008). 
Costa et al. (2008) observaram que o potássio quando interagido com o $\mathrm{N}$ promoveu aumento dos teores de $\mathrm{N}$ nos tecidos foliares de $U$. brizanta cv. Xaraés, o que é importantíssimo devido às funções exercidas por este último elemento no metabolismo vegetal. No mesmo estudo a adubação potássica aumentou a concentração de $\mathrm{K}$ nos tecidos foliares mesmo quando os teores de $\mathrm{K}$ no solo eram altos, contribuindo assim para uma maior exportação de $\mathrm{K}$ e posterior absorção do elemento pelos animais.

$\mathrm{O} \mathrm{K}^{+}$não tem função estrutural na planta, mas é um ativador de funções enzimáticas e de manutenção da turgidez das células, atuando na movimentação de fotoassimilados nos tecidos vegetais, podendo aumentar o valor nutritivo das forrageiras (Raji, 1991). Sua aplicação favorece o perfilhamento influenciando positivamente a quantidade de MS a ser produzida por área (Souza et al., 2007). Mattos \& Monteiro (1998) observaram que o incremento nas doses de potássio na solução nutritiva provocou aumento no rendimento de matéria seca da parte aérea da planta e das raízes do capim $U$. brizantha, com a máxima produção ocorrendo entre 365 e 399 mg.kg. $L^{-1}$ de solução. $O$ perfilhamento das plantas foi alterado pelo suprimento de potássio na solução, com o maior número de perfilhos ocorrendo em 312 e 468 mg.kg.L. ${ }^{-1}$. Sugerindo assim que a utilização do $\mathrm{K}^{+}$não serve apenas para manter a pastagem produtiva, mas também uniformizar a área com boa cobertura vegetal.

\section{Adubações alternativas para forragens}

Não é de hoje que se buscam novas técnicas de adubações para forrageiras, em primeiro lugar a preocupação com as fontes finitas de minerais. Em segundo, as complicações ambientais geradas pelo mau uso dos fertilizantes sintéticos e, por fim, os desperdícios e a poluição dos solos e água pela falta de aproveitamento dos resíduos gerados nos mais variados sistemas de produção tem despertado a necessidade da criação de novas estratégias no que diz respeito à adubação das forrageiras.

Segundo Basso et al. (2013) a vinhaça, resíduo do processo de destilação do álcool é rica em potássio $(\mathrm{K})$ e sua aplicação ao solo pode aumentar a disponibilidade do nutriente $\mathrm{e}$ também provocar alterações nas propriedades químicas do solo. Em estudo realizado pelos mesmos autores, ao comparar fontes de $\mathrm{K}$ sendo a vinhaça uma delas, e doses $\left(\mathrm{m}^{3}\right)$ aplicadas em aveia-preta, milho silagem, milho safrinha, verificou-se que para o cultivo de aveia preta a aplicação de $100 \mathrm{~m}^{3} \mathrm{ha}^{-1}$ proporcionou os maiores acúmulos de massa seca ha ${ }^{-1}$. E nos cultivos de milho safra e safrinha a aplicação de vinhaça na dosagem de $100 \mathrm{~m}^{3} \mathrm{ha}^{-1}$ proporcionou produtividade de silagem semelhante à adubação mineral e foi capaz de suprir a necessidade de potássio também para o cultivo do milho safrinha. Mostrando-se assim, a sua utilização na lavoura, uma alternativa tecnicamente viável para o descarte desse resíduo.

Medina et al. (2009) analisando o comportamento agronômico da cana-de-açúcar da variedade RB 785148, cultivada em Latossolo Vermelho, tratada com doses crescentes de vinhaça em Londrina-PR, observaram aumento da produtividade de colmos com o aumento da dose de vinhaça até $300 \mathrm{~m}^{3} \mathrm{ha}^{-1}$, enquanto doses superiores provocaram redução na produtividade da cana. Quanto ao sistema radicular, foi observado comportamento linear crescente à medida que a quantidade de vinhaça aplicada foi aumentada até a dose $600 \mathrm{~m}^{3} \mathrm{ha}^{-1}$.

Cabe ressaltar que a aplicação excessiva de vinhaça nos sulcos do solo e nos locais de perfilhamento causa lixiviação dos nutrientes contidos na mesma, principalmente do $\mathrm{K}$ devido sua alta mobilidade, além do risco de salinização pela concentração de sais que ocorre devido a este excesso, necessitando assim da fertirrigação ser parcelada e controlada.

Alternativas como a aplicação de águas residuárias da bovinocultura (ARB) e suinocultura (ARS) tem sido empregadas para melhorar as condições do solo e a produção das forrageiras. Erthal et al. (2010) observaram que os valores de $\mathrm{pH}$, CTC, saturação por bases e concentrações de $\mathrm{P}, \mathrm{K}, \mathrm{Ca}$ e $\mathrm{Mg}$, aumentaram com acréscimos nas taxas de aplicação da ARB, nas camadas superficiais do solo, não ocasionando salinização do perfil do solo. Nogueira \& Silva (2006) ressaltaram que as ARS podem ser utilizadas em áreas de cultivo agrícola, por constituírem uma rica fonte de nutrientes, porém as lâminas a serem aplicadas deverão ser calculadas com base na quantidade de nutrientes e outros sais que serão incorporados no solo.

Menezes et al. (2009) constataram que a aplicação de dejetos líquidos de suínos $\left(150 \mathrm{~m}^{3}\right.$ $\mathrm{ha}^{-1}$ ) promoveu acréscimo na produção de massa seca do Capim marandu em $34,2 \%$ e $32,1 \%$ em 
relação à testemunha (sem adubação), adubação mineral (75-30-100 $\mathrm{kg} \mathrm{ha}^{-1}$ de $\mathrm{N}^{-} \mathrm{P}_{2} \mathrm{O}_{5}-\mathrm{K}_{2} \mathrm{O}$ ) respectivamente, verificaram também que as produtividades do capim Tifton adubado, independente da origem da fonte (orgânica ou mineral) não diferiram, mostrando assim que os resíduos orgânicos (cama de frango e dejetos líquidos de suínos) nas doses que foram utilizadas podem substituir a adubação mineral.

Benedetti et al. (2009), ao adubar pastagem de Megathyrsus maximum cv. Mombaça com cama de frango e adubo mineral observaram e concluíram que o uso da cama de frango em substituição ao adubo mineral é viável nos sistemas de pastejo de lotação rotacionada no que tange a produtividade e reposição de parte dos nutrientes do solo, uma vez que os teores de matéria seca e as produtividades de massa seca não diferiram estatisticamente assumindo maior valor numérico para o tratamento com dose única de cama de frango antes dos ciclos de pastejo.

Estudos mais detalhados dos efeitos de fontes alternativas de adubação sobre a produção de forrageiras, bem como sobre as propriedades físico-químicas do solo precisam ser elaborados para fortalecimento dos dados obtidos até o presente momento, visando aperfeiçoar o desenvolvimento vegetal, diminuir os custos de produção e minimizar os impactos ambientais oriundos do descarte inadequado dos resíduos agrícolas.

\section{Consorciação entre gramíneas e leguminosas em áreas pastoris}

Durante muitos anos o cultivo de espécies forrageiras solteiras foi empregado nas áreas de pastagens brasileiras; no entanto as variações abruptas nas condições climáticas, as altas taxas de lotação das pastagens e a desuniformidade na distribuição das chuvas tem prejudicado a disponibilidade de forragem ao longo do ano e levado os produtores a adotarem medidas para suprir o fornecimento de volumoso em qualidade e quantidade nos períodos de estacionalidade das forrageiras tradicionais.

A utilização do consórcio entre leguminosas e gramíneas tem sido uma das medidas adotadas pelos produtores, uma vez que traz a expectativa de melhoria da produção animal em comparação à pastagem de gramínea exclusiva com redução dos custos de produção, quando comparados com estas mesmas pastagens submetidas à adubação com nitrogênio mineral (Vieira \& Zanine, 2005).
Andrade et al. (2003) avaliando o desempenho de seis gramíneas( $U$. brizantha $\mathrm{cv}$. Marandu, U. brizantha cv. MG-4, U. decumbens cv. Basilisk, M. maximumcv. Mombaça, Melinis minutiflora e Hyparrhenia rufa), solteiras ou consorciadas com Stylosanthes guianensis cv. Mineirão e eucalipto em sistema silvipastoril, verificaram que na maioria dos consórcios analisados, com exceção dos consórcios com a $U$. brizantha cv. Marandu e a $U$. decumbens em que a participação da leguminosa foi muito reduzida, houve tendência de maior produção de forragem do que as respectivas gramíneas em monocultura, demonstrando que a presença da leguminosa contribuiu para a produtividade do sistema.

A fixação de nitrogênio pelas leguminosas forrageiras contribui para a auto-suficiência de $\mathrm{N}$ em consorciações, pois proporciona uma fonte de $\mathrm{N}$ não mineral para ser transferido para a gramínea consorciada. A transferência de $\mathrm{N}$ da leguminosa para gramínea pode ser um fato previsto pelo maior vigor e coloração mais verde da gramínea quando esta se encontra crescendo adjacente a leguminosa comparada com a gramínea crescendo afastada da leguminosa (Mesquista, 2001). Costa (2011) verificou maior teor de matéria seca nas silagens de milho consorciado com leguminosas comparado à silagem de milho em consórcio com capim Braquiária, possivelmente a maior quantidade de capim Braquiária, que possui menores teores de MS quando comparado ao milho $\mathrm{e}$ as leguminosas contribui para o menor teor de matéria seca da silagem de milho consorciado com a gramínea.

Além do maior teor de proteína bruta, em geral, as leguminosas tropicais apresentam menor proporção de parede celular, e a digestibilidade da matéria seca é semelhante ou maior que a registrada nas gramíneas tropicais, para um mesmo estádio de desenvolvimento e condição de cultivo. A formação de pastagens consorciadas ou como bancos de proteína constituem as principais formas de utilização de leguminosas no Brasil, América Latina, Austrália e Ásia em sistemas pastoris. Alguns trabalhos indicam aumentos no ganho ou manutenção do peso de animais durante o período da seca, como resultado da melhor qualidade da leguminosa em associação com gramíneas (Barcellos et al., 2008).

Lascano \& Avila (1991) analisando um conjunto de resultados de desempenho animal em 
pastagens puras e consorciadas, afirmaram que as leguminosas selecionadas para solos ácidos, característico do cerrado brasileiro, em consórcio com gramíneas, contribuíram para o aumento de $20 \%$ para $30 \%$ da produção de leite em vacas alimentadas em regime de pastejo. Barcellos \& Vilela (2001) avaliaram a $U$. decumbens em consórcio com $S$. guianensis cv. Mineirão e $U$. brizantha cv. Marandu complementado com banco de proteína dessa leguminosa, e verificaram que a lotação média de ambas as pastagens foi de 1,47 unidades animal/ha durante o período de avaliação (1UA $=450 \mathrm{~kg}$ de peso vivo). $\mathrm{Na}$ estação seca houve a elevação na lotação devido à oferta de forragem existente no banco de proteína justificando assim seu uso em pastagens tropicais.

Em pastagens de Cenchrus ciliares consorciadas com Leucena leucocephala foi possível elevar a lotação de quatro para seis borregos/ha, sem redução do ganho individual de peso dos animais, com consequente aumento da produção por unidade de área (Souza \& Espíndola, 2000).

Além de melhorar as condições físicoquímicas do solo, as características bromatólogicas das forragens e aumentar a taxa de lotação das pastagens, as leguminosas possuem ainda potencial para sequestro de carbono nesses ecossistemas, através da produção primária vegetal, de modo a manter o C (carbono) aprisionado nos troncos e galhos de árvores durante seu crescimento (Paulino \& Teixeira, 2009). Muitos estudos conduzidos no Brasil têm apontado o papel positivo das leguminosas no aumento do C orgânico do solo, favorecendo o desenvolvimento das forrageiras e tornando cada vez mais sustentável a pecuária nacional.

\section{Considerações finais}

O elevado crescimento populacional e a competitividade dos países em desenvolvimento exigem que os sistemas produtivos utilizados na pecuária nacional, se intensifiquem constantemente, na tentativa de produzir maior quantidade de proteína animal em áreas de fertilidade limitada e que se encontram sob alguma forma de degradação. Frente a esse desafio, as inovações tecnológicas no manejo da adubação de pastagens surgem como medidas alternativas nos sistemas de produção, com o intuito de maximizar os ganhos na pecuária, diminuir os custos decorrentes da cadeia produtiva, apresentando ainda potencial para a preservação da vegetação local e recomposição da biodiversidade em sistemas pastoris.

\section{Referências Bibliográficas}

Andrade, C., Garcia, R., Couto, L., Pereira, O. G. \& Souza, A. (2003). Desempenho de seis gramíneas solteiras ou consorciadas com o Stylosanthes guianensis cv. Mineirão e eucalipto em sistema silvipastoril. Revista Brasileira de Zootecnia, 32, 1845-1850.

Barcellos, A. O., Ramos, A. K. B., Vilela, L., Junior, M. \& Bueno, G. (2008). Sustentabilidade da produção animal baseada em pastagens consorciadas e no emprego de leguminosas exclusivas, na forma de banco de proteína, nos trópicos brasileiros. Revista Brasileira de Zootecnia, 37, 51-67.

Barcellos, A. O. \& Vilela, L. (2001). Restabelecimento da capacidade produtiva de pastagens por meio de introducao de Stylosanthes guianensis cv. Mineirao. Embrapa Cerrados. Comunicado Técnico, 65.

Basso, C. J., Santi, A. L., Lamego, F. P., Somavilla, L. \& Brigo, T. J. (2013). Vinhaça como fonte de potássio: resposta da sucessão aveia-preta/milho silagem/milho safrinha e alterações químicas do solo na Região Noroeste do Rio Grande do Sul. Ciência Rural, 43, 596-602.

Benedetti, M. P., Fugiwar, A.T., Factori, A. A., Costa, C. \& Meirelles, P. R. L. (2009). Adubação com cama de frango em pastagem.In: AnaisZootec.Faculdade de Zootecnia e Engenharia Agronômica. Águas de Lindóia, São Paulo, 1-3.

Benício, L. P. F., Oliveira, V. A., Silva, L. L., Rosanova, C. \& Oliveira, S. L. (2011). Produção de Panicum maximum consorciado com sorgo sob diferentes fontes de fósforo. Tecnologia \& Ciência Agropecuária, 5, 5560.

Contin, T. L. M. (2007). (Dissertação de Mestrado). Ureia tratada com o inibidor da urease NBPT na adubação de cana-de-açúcar colhida sem despalha a fogo. Instituto Agronômico de Campinas, São Paulo, Brasil. 
Costa, C. H. M. (2011). Efeito residual da aplicação superficial de calcário e gesso nas culturas de soja, aveia-preta e sorgo granífero. Dissertação de Mestrado. Faculdade de Ciências Agronômicas da UNESP, Botucatu, São Paulo, Brasil.

Costa, K. A. P., Faquin, V., Oliveira, I. P., Araújo, J. L. \& Rodrigues, R. B. (2008). Doses e fontes de nitrogênio em pastagem de capim-marandu: II-nutrição nitrogenada da planta. Revista Brasileira de Ciência do Solo, 32, 1601-1607.

Costa, M. N. X., Mattos, H. B., Bueno, M. F., Santos, C. T. D. \& Leite, V. B. O. (2001). Influência de épocas e doses de adubação nitrogenada na produção estacional do capim Brachiaria humidicola. Boletim de Indústria Animal, 58, 153-167.

Costa, P. M. (2011). Consórcio Capimbraquiária, milho e leguminosas: produtividade, qualidade das silagens e desempenho animal. Dissertação de Mestrado. Universidade Federal dos Vales do Jequitinhonha e Mucuri, Diamantina, Minas Gerais, Brasil.

Dias-Filho, M. B. (2014). Diagnóstico das pastagens no Brasil. Embrapa Amazônia Oriental. Documentos, 402.

Erthal, V. J., Ferreira, P. A., Matos, A. \& Pereira, O. G. (2010). Alterações físicas e químicas de um Argissolo pela aplicação de água residuária de bovinocultura. Revista Brasileira de Engenharia Agrícola e Ambiental, 14, 467-477.

Fageria, N. K., Barbosa-Filho, M. P. \& Stone, L. F. (2004). Nutrição de fósforo na produção de feijoeiro. In: Yamada, T. \& Abadía, S. R. S. Potafós. (Ed.) Fósforo na agricultura brasileira,Piracicaba, São Paulo, Brasil, 435455.

Felipe, R. S. (2012). Alterações nos atributos químicos do solo com aplicação de agrosilício no consórcio milho e braquiária. Dissertação de Mestrado. Universidade Federal de Viçosa, Minas Gerais, Brasil.

Ferraz, J. B. S. \& Felício, P. E. (2010). Production systems - An example from Brazil. Meat Science, 84, 238-243.

Fonseca, D. M., Martuscello, J. A. \& Santos, M. E. R. (2011). Adubação de pastagens: inovações e perspectivas. In: Anais do XXI
Congresso Nacional de Zootecnia. Universidade Federal de Alagoas, Brasil, 113.

Fruchi, V. M., Figueiredo, A. M., Ramos, S. B., Coutinho, E. L. M. \& Heinrichs, R. (2007). Gesso agrícola na produtividade da cana-deaçúcar destinada para forragem. Informativo técnico. Faculdade de Zootecnia - Campus de Dracena, São Paulo, Brasil, 01098-01100.

Guina, F. T. C., Gerbásia, T. \& Kalaki, R. B. (2012). O Manejo Correto de Pastagem Representa Ganhos Econômicos e Ambientais. Available in: http://www.agrodistribuidor.com.br/publicaca o.php?id_item=128, São Paulo, Brasil.

Herling, V. R. \& Luz, P. H. C. (2001). Adubação de Pastagens, saiba por quê?. In: Apostila de adubação de pastagens, Pirassununga, São Paulo, Brasil.

Gatiboni, L. C., Kaminski, J., Pellegrini, J. B. R. \& Aquino, J. E. R. (2013). Efeito da adubação fosfatada e da calagem sobre a qualidade bromatológica da forragem de pastagem natural com introdução de espécies forrageiras de inverno. Revista Brasileira de Agrociência, $14,125-134$.

Guedes, S. E. M., Fernandes, A. R., Lima, E. V., Gama, M. A. P. \& Silva, A. L. P. (2009). Fosfato natural de Arad e calagem e o crescimento de Brachiaria brizanta em Latossolo Amarelo sob pastagem degradada na Amazônia. Revista Ciências Agrárias, 117129.

Krolow, R. H., Mistura, C., Coelho, R. W., Siewerdt, L. \& Zonta, É. P. (2004). Composição bromatológica de três leguminosas anuais de estação fria adubadas com fósforo e potássio. Revista Brasileira de Zootecnia, 33, 2231-2239.

Lascano, C. \& Avila, P. (1991). Potencial de producción de leche en pasturas solas y asociadas con leguminosas adaptadas a suelos ácidos. Pasturas Tropicales, 13, 2-10.

Leão, D. A. S. (2006). Estresse hídrico e adubação fosfatada no desenvolvimento inicial e na qualidade da forragem da gliricídia (Gliricidia sepium (Jacq.) Steud.) e do sorgo (Sorghum bicolor (L.) Moench.). Dissertação de Mestrado, Universidade Federal de Campina Grande, Paraíba, Brasil. 
Lima, S. O., Fidelis, R. R. \& Costa, S. J. (2007). Avaliação de fontes e doses de fósforo no sul do Tocantins. Pesquisa Agropecuária Tropical, 37, 100-105.

Mattos, W. T. \& Monteiro, F. A. (1998). Respostas de Braquiária brizantha a doses de potássio. Scientia Agricola, 55, N3.

Medina, C. C., Neves, C. S. V. J., Batista Fonseca, I. C. \& Torreti, A. F. (2009). Crescimento radicular e produtividade de cana-de-açúcar em função de doses de vinhaça em fertirrigação. Semina: Ciências Agrárias, 23, 179-184.

Menezes, J. F. S., Freitas, K. R., Carmo, M. L., Santana, R. O., Freitas, M. B. \& Peres, L.C. (2009). Produtividade de massa seca de forrageiras adubadas com cama de frango e dejetos líquidos de suínos. In: Anais do I Simpósio Internacional sobre Gerenciamento de Resíduos de Animais, Florianópolis, Santa Catarina, Brasil, 322-327.

Mesquita, E. E. (2001). Fixação simbiótica e processos de transferência de nitrogênio das leguminosas para as gramíneas associadas. Apostila de forragicultura, 1-10.

Mesquita, E., Fonseca, D., Pinto, J. C., Nascimento Jr, D. \& Pereira, O. G. (2002). Métodos de estabelecimento e doses de calcério, gesso e fésforo na produgao e qualidade de Brachiaria decumbens e Stylosanthes guianensis. Pasturas Tropicales, 24, 8-13.

Moreira, L. M. (2000). Características estruturais do pasto, composição química e desempenho de novilhos em pastagem de Brachiaria decumbens cv. Basilisk adubada com nitrogênio. Tese de Doutorado, Universidade Federal de Viçosa, Minas Gerais, Brasil.

Nogueira, C. C. P. \& Silva, I. J. O. (2006). Aplicação de águas residuárias de suinocultura na irrigação. Thesis, 6, 18-29.

Oliveira, I. P., Costa, K. A. P., Faquin, V., Maciel, G. A., Neves, B. P. \& Machado, E. L. (2009). Efeitos de fontes de cálcio no desenvolvimento de gramíneas solteiras e consorciadas. Ciência Agrotecnologia, 33, 592-598.

Patês, N. M. S., Pires, A. J. V., Silva, L. C. S., Carvalho, G. G. P. \& Freire, M. L. A. (2007). Características morfogênicas e estruturais do capim-tanzânia submetido a doses de fósforo e nitrogênio. R. Bras. Zootec, 36, 1736-1741.

Paulino, V. T. \& Teixeira, E. M. L. C. (2009). Sustentabilidade de pastagens - manejo adequado como medida redutora da emissão de gases de efeito estufa. Comunicado técnico. CPG- Produção animal sustentável, Ecologia de Pastagens, Nova Odessa, São Paulo, Brasil.

Politi, L. S. \& Prado, R. M. (2009). Fósforo na nutrição e na produção de massa do capimTanzânia. Revista da FZVA, 16, 95-104.

Prado, R. M. \& Fernandes, F. M. (2000). Escória de siderurgia e calcário na correção da acidez do solo cultivado com cana-de-açúcar em vaso. Scientia Agricola, 57, 739-744.

Prado, R. M., Fernandes, F. M. \& Natale, W. (2003). Efeito residual da escória de siderurgia como corretivo de acidez do solo na soqueira de cana-de-açúcar. Revista Brasileira de Ciência do Solo, 27, 287-296.

Raij, B. V. (1991). Fertilidade do solo $e$ adubação. Ed. Ceres/Potafos, Piracicaba, São Paulo, Brasil, 343 p.

Santos, A. R., Neto, R. L., Santos, A. C. \& Santos, L. G. (2009). Evolução, adubação e diagnose nutricional de pastagens. In: Carvalho, C. A. L., Dantas, A. C. V. L., Pereira, F. A. C., Soares, A. C. F., Melo Filho, J. F. \& Oliveira, G. J. C. 2009. Tópicos em ciências agrárias. Universidade Federal do Recôncavo da Bahia, Centro de Ciências Agrárias, Ambientais e Biológicas: Gráfica e Editora Nova Civilização Ltda, Cruz das Almas, Bahia, Brasil, 171-181.

Santos, A. S., Dias, D. G., Pegoraro, R. F., Porto, E. M. V., Alves, D. D., Carvalho, M. A. M. \& Sales, R. P. (2012). Produção da massa seca da parte aérea e da raiz do Capim Piatã submetido a diferentes fontes de fósforo.In: Anais doXIV Seminário de Pesquisa e PósGraduação. XII - Seminário de Iniciação Científica. IV Seminário PIBID.Universidade Estadual de Montes Claros, Minas Gerais, Brasil.

Santos, M. E. R. (2010). Adubação de pastagens: possibilidades de utilização. Enciclopédia Biosfera, 6, 1-15.

Sichocki, D., Wehren, D. H., Volf, M. R., Wruck, F. J., Ribeiro, J. F. Silva, W. B., Segate, T. \& Silva, L. S. (2010). Índice SPAD e 
produtividade de milho sob efeito de ureia protegida e comum em diferentes dosagens. In: Anais FERTBIO, XXIX Reunião Brasileira de Fertilidade do Solo e Nutrição de Plantas, Guarapari, Espírito Santo, Brasil, 1-3.

Sousa, D. M. G., Vilela, L., Lobato, E. \& Soares, W. V. (2001). Uso de gesso, calcário e adubos para pastagens no cerrado. Embrapa Cerrados, Brasília.

Sousa, R. S., Pires, A. J. V., Carvalho, G., Silva, F., Magalhães, A. F. \& Veloso, C. M. (2010). Composição química de capim-tanzânia adubado com nitrogênio e fósforo. Revista Brasileira de Zootecnia, 39, 1200-1205.

Souza, A. A. \& Espíndola, G. B. (2000). Bancos de proteína de leucena e de guandu para suplementaçao de ovinos mantidos em pastagens de Capim-Buffel. Revista Brasileira de Zootecnia, 29, 365-372.

Souza, M. R. F., Pinto, J. C., Oliveira, I. P., Muniz, J. A., Rocha, G. P. \& Evangelista, A. R. (2007). Produção de forragem do capimtanzânia sob intervalos de corte e doses de potássio. Ciência e Agrotecnologia, 31, 1532 1536.

Stocco, F. C., Passos, R. R., Andrade, F. V., Reis, E. F., Souza Lima, J. S., Santos, D. A. \& Machado, R. V. (2010). Uso de escórias de siderurgia na produção de matéria seca e perfilhamento de duas gramíneas do gênero Brachiaria em um latossolo vermelhoamarelo. Bioscience Journal, 26, 240-248.
Teixeira, F. A., Bonomo, P., Pires, A. J. V., Silva, F., Fries, D. D. \& Hora, D. (2011). Produção anual e qualidade de pastagem de Brachiaria decumbens diferida e estratégias de adubação nitrogenada. Acta Scientiarum. Animal Sciences, 33, 241-248.

Torres, J. L. R. \& Pereira, M. G. (2008). Dinâmica do potássio nos resíduos vegetais de plantas de cobertura no cerrado. Revista Brasileira de Ciência do Solo, 32, 1609-1618.

Vieira, B. R. \& Zanine, A. M. (2005). Espécies forrageiras cultivadas no extremo-sul da Bahia e sua utilização na bovinocultura: um enfoque na consorciação gramínea / leguminosa. Revista científica eletrônica de agronomia, 4, 1-12.

Vilela, H. (2009). Renovação e Manutenção de Pastagens.Avaliable in: http://www.agronomia.com.br/conteudo/artig os/artigos renovacao manutencao pastagens. $\underline{\mathrm{htm}}$, Belo Horizonte, Minas Gerais, Brasil.

Recebido em Setembro 29, 2015

Aceito em Novembro 28, 2015

License information: This is an open-access article distributed under the terms of the Creative Commons Attribution License, which permits unrestricted use, distribution, and reproduction in any medium, provided the original work is properly cited. 